\title{
A bacteriological study of non-chromogenic variants of Serratia marcescens from human sources
}

\author{
H. R. ELSTON \\ From the Microbiology Research Laboratory, Veterans Administration Hospital, \\ Omaha, Nebraska, U.S.A.
}

SYNOPSIS The culture and biochemical features of 10 non-chromogenic variants of $S$. marcescens isolated from clinical sources are reported. Autoagglutination titres were significantly high in sera from those patients in whom Serratia bacilli appeared to contribute to the illness. Since the taxonomic stature of the Serratia bacilli is not clear it might be better to limit the identification of this group to Serratia species.

Serratia bacilli are usually considered saprophytes whose natural habitat is soil, water, sewage, and food. Recently, these organisms have been described as opportunist pathogens which under certain conditions of increased susceptibility of the host can cause disease, and on rare occasions death (Wheat, Zuckerman, and Rantz, 1951; Patterson, Banister, and Knight, 1952; Haiby, McFarland, and Moore, 1961). Serratia strains have been invariably recognized by their pigment production, and have been classified by the colour of the pigment produced and by their growth and biochemical characteristics (Hefferan, 1903-04; Breed, Murray, and Smith, 1957; Topley and Wilson, 1955). Although the existence of non-chromogenic strains has long been known, reports of isolations from human infections are sparse in the literature. This may be due, in part, to improper identification of these organisms.

This paper reports an investigation of the cultural and biochemical characteristics of 10 non-pigmented variants of Serratia marcescens which we have found in clinical material from human sources.

\section{MATERIAL AND METHODS}

The source of the Serratia cultures investigated is given in Table I. They were isolated during a six-month period from January to August 1964. Nine strains were from adults and one strain was recovered from the blood of an infant.

MORPHOLOGY Morphological observations were made from Gram-stained smears of 18-to 24-hour cultures. Each strain was examined for capsule formation in India ink preparations. Motility was determined by a modified
TABLE I

SOURCE OF CULTURES

\begin{tabular}{|c|c|c|}
\hline $\begin{array}{l}\text { Strain } \\
\text { Number }\end{array}$ & Source & Clinical Diagnosis \\
\hline $\begin{array}{l}1456 \\
2352 \\
2472 \\
2559 \\
2634 \\
2749 \\
2835 \\
3116 \\
3405 \\
3441\end{array}$ & $\begin{array}{l}\text { Blood } \\
\text { Blood } \\
\text { Urine } \\
\text { Sputum } \\
\text { Urine } \\
\text { Wound } \\
\text { Urine } \\
\text { Urine } \\
\text { Sputum } \\
\text { Wound }\end{array}$ & $\begin{array}{l}\text { Septicaemia } \\
\text { Septicaemia } \\
\text { Urinary tract infection } \\
\text { Respiratory infection } \\
\text { Urinary tract infection } \\
\text { Osteomyelitis, right femur } \\
\text { Without known clinical significance } \\
\text { Urinary tract infection } \\
\text { Without known clinical significance } \\
\text { Post-operative infection }\end{array}$ \\
\hline
\end{tabular}

hanging-drop technique from a six-to 18-hour tryptone broth culture (Difco).

GROWTH METHODS Primary cultures were grown on Brewer's modified thioglycollate medium ${ }^{1}, 4 \%$ human blood-trypticase soy agar ${ }^{1}$, and MacConkey agar (Difco) at $37^{\circ} \mathrm{C}$. The growth rate was determined at 25,37 , and $42^{\circ} \mathrm{C}$. on nutrient agar slants. Four media inoculated in duplicate and incubated at 25 and $37^{\circ} \mathrm{C}$. were used in surveying each strain's ability to produce pigment; potato agar', Gessard's glycerol peptone agar stabs (Seleen and Stark, 1943), peptone-glycerol-phosphate agar, and broth (Bunting, 1950) were observed daily for five days.

BIOCHEMICAL PROCEDURES The production of oxidase was determined by using a $1 \%$ solution of p-aminodimethylaniline monohydrochloride, while catalase activity was tested by adding 3\% hydrogen peroxide to a fresh agar culture. Difco decarboxylase broth base was used to study lysine, arginine, and ornithine decarboxylase activity. Kligler iron agar containing ferrous sulphate and thiosulphate was used to demonstrate hydrogen sulphide production. Ability to produce hydrogen sulphide was further studied by inserting a lead acetate paper strip ${ }^{1}$ Baltimore Biological Laboratory. 
over the Kliger's slant. This medium also contains $0.1 \%$ glucose, $1 \%$ lactose, and phenol red to indicate fermentation of these sugars. Carbohydrate test media were incubated at $37^{\circ} \mathrm{C}$. and observed for 30 days before they were discarded. Fermentation reactions of each strain were tested using carbohydrates in $1 \%$ concentration in peptone water with bromcresol purple as indicator. Bacto malonate broth was used to detect fermentation of sodium malonate. The oxidation-fermentation medium of Hugh and Leifson (1953) was used to determine oxidative versus fermentative metabolism of glucose. Christensen's (1946) urea agar was used to demonstrate urease activity. Nutrient broth with $12 \%$ gelatin was used to detect gelatinase. Serum liquefaction was tested on Loeffler's coagulated serum slants. Indole production was tested, after growth in $1 \%$ tryptone broth, with Kovacs reagent after extraction with xylene. Both the methyl red and VogesProskauer tests were determined on four-day-old methyl red Voges-Proskauer broth cultures (Difco). The utilization of citrate as the sole source of carbon was demonstrated in Simmons citrate agar slants. Phenylalanine agar was used as the substrate in the test for phenylpyruvic acid. Nitrate broth (Difco) was inoculated in duplicate and the reduction of nitrates to nitrites was tested for at 24 and 72 hours. Reaction in milk was observed in Difco litmus milk.

SERological procedure Agglutination tests using living organisms were performed by adding a saline suspension of micro-organisms (density matched that of a no. 3 McFarland nephelometer tube) to a twofold serial dilution of patient's serum in normal saline. The tubes were incubated for two hours in a $56^{\circ} \mathrm{C}$. water bath and then were read for macroscopic agglutination. They were refrigerated at $5^{\circ} \mathrm{C}$. overnight before a final reading was made.

ANTIBIOTIC SENSITIVITY TESTS The paper disc method was used to determine drug susceptibility. Nutrient agar plates were inoculated with $0.1 \mathrm{ml}$. of a four-to six-hour broth culture and streaked with a cotton swab. Commercial discs of the commonly used antibiotics were added in two concentrations (Table III). The presence or absence of zones of inhibition of growth around each disc was determined after 18 hours' incubation at $37^{\circ} \mathrm{C}$.

PATHOGENICITY FOR ANIMALS The pathogenicity of these Gram-negative bacilli was tested in white mice and rabbits by the intraperitoneal injection of $0.5 \mathrm{ml}$. and $1.0 \mathrm{ml}$. of a 24-hour broth culture. All of the mice died within 24 hours but the rabbits were not affected.

\section{OBSERVATIONS AND RESULTS}

MORPHOLOGY The organisms were found to conform in general to the description as given by Breed et al. (1957). The strains were non-sporulating Gram-negative rods with both coccoid and bacillary forms. Commonly, the bacteria appear singly and in pairs. Capsules were not formed on ordinary media. All of the strains were actively motile in hanging-drop preparations.

GROWTH CHARACTERS In infusion broth, these organisms grew with a heavy turbidity without forming a surface pellicle and with a small amount of grayish white sediment. Colonies on blood agar streak plates were gray, smooth, convex, moist, and glistening with an entire edge. Isolated colonies showed no hacmolysis on blood, but discoloration or haemodigestion occurred where growth was heavy. On MacConkey agar, colonies were colourless and indistinguishable from most other nonlactose-fermenting colonies. Growth was equally profuse at 25 and $37^{\circ} \mathrm{C}$, , but was light or failed to occur at $42^{\circ} \mathrm{C}$. All of our organisms failed to show pigment on primary culture. Nine of the 10 Serratia organisms were stable colourless strains which would not form pigments under any of the conditions tested. One strain (isolated from blood) produced a faint pink colour along the edge of the culture growth at $25^{\circ} \mathrm{C}$. on subculture. The pigment was insoluble in water, but soluble in alcohol, chloroform, and ether.

BIOCHEMICAL STUDIES A summary of the major biochemical characteristics is presented in Table II. Fermentation reaction showed that gas was conspicuously absent except for two strains which produced a bubble of gas in glucose. Acid production in lactose broth was absent or delayed. Variable results were obtained from adonitol and sorbitol. Adonitol when acid was attacked more slowly than the other carbohydrates except lactose. Sorbitol when acid was fermented in 24 to 48 hours. All of the organisms grew well aerobically and anaerobically in the oxidation-fermentation medium of Hugh and Leifson with glucose. Urease was produced slowly in Christensen's urea agar by eight strains on primary culture, a weak reaction developing in 24 hours. Litmus milk was acidified and coagulated in 24 hours with digestion occurring in four to 10 days. Four previously isolated pigmented Serratia cultures exhibited similar biochemical properties throughout and differed only in the production of pigments on primary culture.

SEROLOGICAL STUDIES Blood serum from six patients subjected to agglutination tests with homologous organisms revealed four with agglutinin titres of $1: 160$ or greater when titres of $1: 80$ might be considered significant. Agglutinin titres of the other two patients were $1: 10$ and $1: 40$ and there was no change in titres three weeks after the first titration. It is of interest that these two patients were the same two in whom the isolation of $S$. marcescens (strain 
TABLE II

\begin{tabular}{|c|c|c|c|c|c|c|c|c|c|c|c|c|c|c|}
\hline \multirow{3}{*}{$\begin{array}{l}\text { Number } \\
\text { of } \\
\text { Strains }\end{array}$} & \multirow{3}{*}{$\begin{array}{l}\text { Sucrose } \\
\text { Maltose } \\
\text { Mannitol } \\
\text { Salicin } \\
\text { Inositol } \\
\text { Galactose } \\
\text { Glycerol } \\
\text { Trehalose }\end{array}$} & CHEMIC & CTI & 50 & NON & CHR & GENIC VARIAI & IS OF Serra & ia $m a$ & cescens & & & & \\
\hline & & \multirow{2}{*}{$\begin{array}{l}\text { Xylose } \\
\text { Dulcitol } \\
\text { Arabinose } \\
\text { Raffinose } \\
\text { Rhamnose } \\
\text { Malonate }\end{array}$} & \multirow[b]{2}{*}{$\frac{\check{\Xi}}{\overleftarrow{\Xi}}$} & \multirow[b]{2}{*}{ 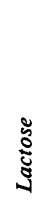 } & \multirow[b]{2}{*}{ 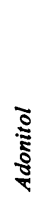 } & \multirow[b]{2}{*}{ ڤั) } & \multirow{2}{*}{$\begin{array}{l}\text { Citrate } \\
\text { Voges-Proskauer } \\
\text { Catalase } \\
\text { Nitrites } \\
\text { Motility } \\
\text { Gelatin } \\
\text { Serum } \\
\text { Liquefaction }\end{array}$} & \multirow{2}{*}{$\begin{array}{l}\text { Indole } \\
\text { Methyl Red } \\
\text { Oxidase } \\
\text { Phenyl- } \\
\text { pyruvic } \\
\text { Acid }\end{array}$} & \multirow[t]{2}{*}{$\mathrm{H}_{2} \mathrm{~S}$} & \multirow[t]{2}{*}{ Urea } & \multirow{2}{*}{$\begin{array}{l}\text { Litmus } \\
\text { Milk }\end{array}$} & \multicolumn{3}{|c|}{ Decarboxylase } \\
\hline & & & & & & & & & & & & 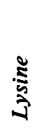 & 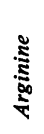 & : \\
\hline 1 & $\mathbf{A}$ & O & $\mathbf{A}_{\mathbf{b}}$ & O & $\mathbf{A}_{\mathrm{s}}$ & $\mathbf{A}$ & + & - & $t_{w}$ & $+w$ & A.C.D. & + & - & + \\
\hline $2^{1}$ & A & O & $\mathbf{A}$ & $\mathbf{O}$ & $\mathbf{A}_{8}$ & A & + & - & $+w$ & - & A.C.D. & + & - & + \\
\hline 2 & A & 0 & $\mathbf{A}$ & 0 & 0 & A & + & - & $+w$ & $t_{w}$ & A.C.D. & + & - & + \\
\hline 1 & A & 0 & $A_{b}$ & $\mathbf{A}_{\mathbf{s}}$ & $\mathbf{A}_{\mathbf{s}}$ & A & + & - & $+w$ & $+w$ & A.C.D. & + & - & + \\
\hline 2 & $\mathbf{A}$ & O & $\mathbf{A}$ & $\mathbf{A}_{\mathbf{s}}$ & $\mathbf{A}_{\mathbf{s}}$ & $\mathbf{A}$ & + & - & $+w$ & $+w$ & A.C.D. & + & - & + \\
\hline 1 & $\mathbf{A}$ & O & A & $\mathbf{A}_{\mathbf{s}}$ & 0 & A & + & - & $+w$ & $+w$ & A.C.D. & + & - & + \\
\hline 1 & A & O & A & $\mathbf{O}$ & $\mathbf{O}$ & O & + & - & $+w$ & $+w$ & A.C.D. & + & - & $\perp$ \\
\hline
\end{tabular}

${ }^{1}$ One of these two strains produced a faint pigment on subculture.

$\mathbf{A}=$ Acid without gas. $\mathbf{A}_{\mathbf{b}}=$ acid with bubble of $\mathbf{g a s} ; \mathbf{A}_{\mathrm{s}}=$ acid produced slowly; $+_{\mathbf{w}}=$ weakly positive; $\mathbf{A}$. C.D. $=$ acid, coagulated, digested.

nos. 2835 and 3405 of Table I) was thought to be of no clinical significance.

ANTIBIOTIC SENSITIVITY STUDIES All 10 strains were highly sensitive to kanamycin and neomycin, while nine strains showed some degree of susceptibility to chloramphenicol. Of the semisynthetic penicillins studied, only ampicillin was slightly effective. All 10 organisms were uniformly resistant to penicillin, methicillin, oxacillin, erythromycin, novobiocin, tetracycline, nitrofurantoin, and all of the sulphonamides tested. Results of these studies are listed in Table III.

\section{TABLE III}

DRUG SUSCEPTIBILITY TESTS OF 10 NON-CHROMOGENIC VARIANTS OF Serratia marcescens

Antimicrobial Drug and Disc Sensitive Moderately Resistant $^{3}$ Concentrations Sensitive ${ }^{2}$

Penicillin (2, 10 units)

Methicillin $(5 \mu \mathrm{g}$.)

Oxacillin $(1 \mu \mathrm{g}$.

Ampicillin $(2,10 \mu \mathrm{g}$.

Streptomycin $(2,10 \mu \mathrm{g}$.)

Tetracycline $(5,30 \mu \mathrm{g}$.

Chloramphenicol $(5,30 \mu \mathrm{g}$.)

Erythromycin (2, $15 \mu \mathrm{g}$.)

Novobiocin $(5,30 \mu \mathrm{g}$.)

Kanamycin $(5,30 \mu g$.

Neomycin $(5,30 \mu \mathrm{g}$.

Colistin (2, $10 \mu \mathrm{g}$.

Polymyxin (50, 300 units)

Nitrofurantoin $(100 \mu \mathrm{g}$.

Gantrisin $(0.25,1.0 \mathrm{mg}$.

Sulphadiazine $(0.25,1.0 \mathrm{mg}$.

Sulphathiazole $(0.25,1.0 \mathrm{mg}$.)

'Sensitive $=$ growth inhibited by both concentrations

${ }^{2}$ Moderately sensitive $=$ growth inhibited by higher concentration

${ }^{3}$ Resistant $=$ growth not inhibited by either concentration

RESUlts OF ANIMAL VIRULENCE TESTS The Serratia bacilli were lethal to white mice. Necropsy revealed no gross abnormalities of the internal organs except serous peritonitis. On microscopy the liver, spleen, kidneys, and adrenals were normal. Smears taken from the heart blood and peritoneal exudate showed many Gram-negative bacilli. Organisms recovered in pure culture from the heart blood, peritoneal fluid, liver, spleen, and kidneys were identified culturally and by slide agglutination tests as $S$. marcescens. The rabbits showed no signs of illness during a period of observation of one month.

\section{DISCUSSION}

Non-chromogenic variants of $S$. marcescens have generally not been recognized in culture studies until the last few years. This may be due to the emphasis that has been placed on the association of pigmentation with Serratia colonies. The increased isolation of these bacilli in our laboratory is, at least in part, related to the increased use of definitive tests to identify Gram-negative bacilli.

Non-pigmented strains of $S$. marcescens may be confused with several members of the Enterobacteriaceae family. Only by routine use of a battery of bacteriological tests can these bacilli be separated from other enteric bacteria and properly identified. Colonial morphology on blood agar is quite similar to other enteric organisms, while growth on MacConkey agar resembles that of the non-lactose fermenters. It is probable that cultures of nonchromogenic $S$. marcescens have been mistaken for anaerogenic Paracolobactrum species (especially the Hafnia group) or for Aerobacter cloacae, Aerobacter subgroup C (liquefaciens), and, to a lesser extent, for other members of the Klebsiella-aerogenes group. Non-chromogenic $S$. marcescens strains differ from the paracolon group in failing to ferment xylose, arabinose, or rhamnose, and by the rapid liquefaction of gelatin in 24 hours. In addition, cultures of the Hafnia group ferment malonate, and fail to ferment inositol or sorbitol. Some of the paracolon 
bacilli give variable indole, methyl red, VogesProskauer, and citrate reactions whereas $S$. marcescens almost always give uniform results $(--++)$. Aerobacter cloacea is similar in IMVic (indole, methyl red, Voges-Proskauer, citrate) and gelatin reactions even though the latter reaction is slower. Also, $A$. cloacae ferments rhamnose, while $S$. marcescens does not. Aerobacter subgroup C organisms may be distinguished from Serratia bacilli mainly through their ability to ferment arabinose and raffinose. Some Aerobacter strains, such as Aerobacter subgroup C, produce similar decarboxylase activity. The key features which appear to differentiate $S$. marcescens from these closely related Aerobacter strains are their anaerogenic nature and failure to produce acid from xylose, arabinose, or raffinose.

In contrast to the findings of Fulton, Forney, and Leifson (1959), we were unable to demonstrate non-motile, gelatin-negative, and arabinose-positive strains. On the contrary, we found distinct motility on primary isolation and rapid liquefaction of gelatin within 24 hours as key identifying characters. With the exception of urease production by some of our strains, other biochemical characteristics are in agreement with those noted by Fulton et al. (1959; Bövre and Tönjum, 1963). Some of the strains that produced weak urease reactions on initial isolation in the weakly buffered urea agar tend to lose urease activity on subculture. Weak acid reactions may occur in fermentation media which may result in a reversion of the $p \mathrm{H}$ to the alkaline side. This was particularly true with salicin and adonitol. Non-chromogenic variants of $S$. marcescens may be best characterized by their anaerogenic nature, motility, rapid liquefaction of gelatin, ability to produce small amounts of $\mathrm{H}_{2} \mathrm{~S}$ on lead acetate paper, production of acid from glucose, sucrose, maltose, mannitol, salicin, and absent or delayed acid from lactose, and lack of fermentative action on xylose, arabinose, rhamnose, raffinose, and malonate.

Most reports of sensitivity studies in vitro attest to the high degree of susceptibility of Serratia to kanamycin and neomycin, but beyond this there are many differences. Because of variable resistance to most antimicrobial agents it seems imperative that sensitivity studies be undertaken for each individual strain.

The role that Serratia may have in producing human infections has not been completely resolved. Serratia has been associated with meningitis, septicemia, endocarditis, urinary and respiratory tract infections, bronchiectasis, otitis media, sinusitis, skin and wound infections, Eight of the strains reported here were thought to have contributed to the patient's illness. Further clinical evaluation may rest with the recognition of non-chromogenic Serratia strains on culture.

The taxonomic stature of Serratia is not clear as evidenced by the differences in present day classification schemes (see Breed et al., 1957; Topley and Wilson, 1955). Pigmentation can nolonger be regarded as a prime requisite for classification. Antigenic studies, such as those in progress at the Communicable Disease Centre (Ewing, Davis, and Reavis, 1959), may give a clearer picture of the taxonomic position of these organisms. It might be worthwhile at the present time to limit the identification of these bacteria to Serratia species.

\section{REFERENCES}

Bövre, K., and Tönjum, A. M. (1963). Acta path. microbiol. scand., 58, 251 .

Breed, R. S., Murray, E. G. D., and Smith, N. R. (1957). Bergey's Manual of Determinative Bacteriology, 7 th ed., p. 359. Williams and Wilkins, Baltimore.

Bunting, M. I. (1950). J. Bact., 59, 241.

Christensen, W. B. (1946). Ibid., 52, 461.

Ewing, W. H., Davis, B. R., and Reavis, R. W. (1959). CDC Laboratory Manual. Communicable Disease Center, Atlanta, Georgia.

Fulton, M., Forney, C. E., and Leifson, E. (1959). Canad. J. Microbiol., 5, 269.

Haiby, G., McFarland, R. B., and Moore, G. H. (1961). Amer. J. clin. Path., 36, 256.

Hefferan, M. (1903-04). Zl. Bakt. (II Abt.), 11, 397 and 520.

Hugh, R., and Leifson, E. (1953). J. Bact., 66, 24.

Patterson, R. H. Jr., Banister, G. B., and Knight, V. (1952). Arch. intern. Med., 90, 79.

Seleen, W. A., and Stark, C. N. (1943). J. Bact., 46, 491.

Topley, W. W. C., and Wilson, G. S. (1955). Principles of Bacteriology and Immunity, 4th ed., revised by G. S. Wilson and A. A. Miles, vol. 1, p. 726. Williams and Wilkins, Baltimore.

Wheat, R. P., Zuckerman, A., and Rantz, L. A. (1951). Arch. intern. Med., 88, 461. 